\title{
Occupational Noise Exposure to Masonry Saw Cutting Materials
}

\author{
Adriano A. R. Barbosa*, Stelamaris R. Bertoli \\ Federal Institute of Sao Paulo \& School of Civil Engineering, University of Campinas, PO Box 6021, Campinas City, \\ São Paulo State 13083-970, Brazil \\ *Corresponding author: adriano@ifsp.edu.br
}

\begin{abstract}
Despite a widespread recognition of the impacts of noise on hearing and other aspects of health, noise exposure in industry remains a significant problem, especially in the construction industry where noise exposure levels of workers are high, especially due to the use of manual equipment and machines used in constructions sites. The masonry saw is a portable power tool widely used in construction in small cuts and finishes for floors, tiles, bricks and woods. It stands out for versatility, lightness and its ergonomics. As part of efforts to identify sources of noise pollution from construction, a noise exposure is developed here for the occupational assessment from masonry saws, which are electric cutters that are commonly used in the industry. Different building materials commonly used in Brazil are used with the masonry saw in their conditions of loading and operation. The proposed methodology evaluates the noise generated during cutting with equipment in accordance with ISO 3744:2010 which specifies methods of measuring sound pressure levels on a surface enveloping the noise source in an environment that approximates an acoustic free field over a reflecting plane and the standard ISO 9612:2009 which specifies an engineering method for measuring workers' exposure to noise in a working environment and calculating the noise exposure level. The cutting of different building materials was louder than the disengaged saw. The highest observed sound pressure level was $106.9 \mathrm{~dB}(\mathrm{~A})$ at operator ear and $99.1 \mathrm{~dB}(\mathrm{~A})$ at 2 meters from the source. The smallest difference observed between the cutting and disengaged saw was $7.8 \mathrm{~dB}(\mathrm{~A})$. Noise generated by the saw was quantitatively assessed. An occupational analysis illustrates that the sound levels generated in operations exceeded the tolerances permitted without protection. The subject is relevant to anticipating risks in the workplace in activities with the masonry saw cutting various building materials. Noise excess removal in the workplace is not just a legal responsibility of the companies, as it is also involved with the market interests of an organization. The safer and healthier a workplace is, the fewer probabilities of absenteeism, accidents and low performance, and consequently, cost savings will be achieved. This study also contributes to the analysis of occupational noise generation, considering the difficulties in obtaining previously reported values of the sound spectrum of masonry saws.
\end{abstract}

Keywords: noise, occupational exposure, portable power tools, masonry saw, construction materials

Cite This Article: Adriano A. R. Barbosa, and Stelamaris R. Bertoli, "Occupational Noise Exposure to Masonry Saw Cutting Materials." Journal of Environment Pollution and Human Health, vol. 5, no. 2 (2017): 30-35. doi: 10.12691/jephh-5-2-1.

\section{Introduction}

The noise is one of the harmful agents to the health that is present in the most different economic activity branches. Among the complaints related by workers exposed to occupational noise, there are the loss hearing and the tinnitus. Scientific data show that exposure to occupational noise is one of the factors that most causes hearing loss and tinnitus. As for epidemiology, tinnitus is a problem that affects around $17 \%$ of the world population, increasing its incidence to $33 \%$ in the elderly, causing significant suffering in $4 \%$ of people in general [1]. The World Health Organization recognizes noise pollution as the third most prevalent type of pollution after air and water pollution. The construction industry and its various machines and tools are significant noise makers [2].
Noise from construction is imputed as a contributor to illness and is treated as a public health issue. Research in the United States into the prevention of occupational hearing loss stresses the importance of research and prevention [3]. Construction noise, which is particularly annoying to society, has significant contributions from machines and tools [4]. Brazil's construction sector is one of the country's quickly most expanding according to the research institutes and trade unions for civil construction: some industry data suggest that the number of jobs in this sector has doubled in the last decade [5].

Noise is one of the most highly found physical contaminants in the construction sector. The most negative effects caused by noise exposure are related to the hearing system and may produce professional deafness or even permanent deafness. As these effects have a very important influence on people's health and well-being, it is necessary to assess the noise exposure and to develop 
mechanisms for studying and proposing preventive solutions [6]. Builders seek new processes and materials to reduce the time and labor costs of their work [7]. However, mechanized construction is noisy, with the most powerful equipment often being the loudest [8]. Hand-held electrical equipment is versatile and precise; there is a diverse range of such tools, and they are often inexpensive. They are widely used throughout construction, from infrastructure to finishing and repairs. The masonry saw is a common example. In Brazil, masonry saws are increasingly used for finishing in ceramic plates. The Brazilian Association of Ceramic Tile Manufacturers [9] states that the consumption of ceramic coatings in Brazil doubled in the last decade.

A full assessment of the noise conditions in a loud environment requires knowledge of the noise generated by each particular source. Equipment manufacturers usually provide values of the sound pressure levels measured at a set distance from their equipment. The sound pressure level depends on the conditions of the propagating sound, including the presence of obstacles. Various environmental factors can influence the spread of sound, such as temperature, pressure, and relative humidity. Besides the directivity and source position, the material being worked with can also affect the noise associated with certain equipment. The assessment of both ambient noise and noise from specific pieces of equipment at construction sites is important to the development of quieter practices. Masonry saws are louder when cutting materials than when running freely.

The objective of this paper is to present an assessment of noise exposure and the sound pressure levels generated with the masonry saw in load conditions and operation adopted at construction sites for different construction materials in Brazil.

\section{Characteristics of Masonry Saws and Diamond Abrasive Blades}

\subsection{Masonry Saws}

Masonry saws cut stone, concrete, masonry, ceramics, and glass. They are hand-held and portable. The average power of the motor is $1,400 \mathrm{~W}$ and the removable diamond disk rotates at approximately $12,000 \mathrm{rpm}$. They can cut wet or dry, straight or at angles, and are widely used for minor cuts and floor finishing for tiles, bricks, and wood. Such saws are versatile, practical, light, and ergonomic.

\subsection{Diamond Abrasive Blade}

The diamond abrasive blade that is used with a masonry saw is a metal disk. Its cutting area is either continuous or segmented and set with industrial diamond crystals. Blades must comply with the ABNT NBR 15910:2010 set of specifications [10]: 12.000-14.000 rpm rotation; 110$125 \mathrm{~mm}$ diameter; $20 \mathrm{~mm}$ central bore; $1.4-1.6 \mathrm{~mm}$ thickness; 6-8 $\mathrm{mm}$ diamond height; $1.8-2.2 \mathrm{~mm}$ diamond thickness.

\section{International Standards for Sound Pressure Level and Noise Exposure Measurement}

The standard ISO $3744: 2010$ [11] is part of the ISO 3740 series of standards for assessing sound power levels. It specifies methods of measuring sound pressure levels on a surface enveloping the noise source in an environment that approximates an acoustic free field over a reflecting plane. And the standard ISO 9612:2009 [12] specifies an engineering method for measuring workers' exposure to noise in a working environment and calculating the noise exposure level. This standard deals with A-weighted levels. It is not intended for assessment of masking of oral communication or assessment of infrasound, ultrasound and non-auditory effects of noise. Results of the measurements performed in accordance with this standard can provide useful information when defining priorities for noise control measures.

\section{Materials and Methods}

The cutting operations assessment of masonry saws under conditions closely resembling those found during their regular use. To achieve an authentic simulation of regular use, the tests of this work were conducted while trained builders operated the masonry saws. In this study we sought an employment simulation for analysing behaviour of noise generated in the masonry saw operations under its conditions of loading and operation, where the presence of the operator was required. The choice of the open field was given due to the large amount of dust generated in the cutting of construction materials operations. Was considerate operations with the masonry saw held linear cuts, dry, commonly performed in works in the construction industry.

\subsection{Operations with Masonry Saws}

Masonry saws were used to perform common cutting tasks. The saws and diamond blades were new for the task, in accordance with current standards. The brands and models were readily commercially available and are often used at construction sites. Measurements were performed in an open area of a university campus; the floor was unpaved with some areas of trimmed grass; the surroundings were flat without sources of constructive interference and with low external noise.

\subsection{Measurements and Materials}

For the selection of materials used in cutting operations with marble saw for this search, criteria was that the suppliers were regularly accredited by the Brazilian association of the industry of materials and with similar characteristics to the materials widely used in construction sites in Brazil. We opted to use the most popular and commercialized construction materials on a large scale in companies in the sector. Were utilized in the cutting operation, the following construction materials: 
a) Ceramic Plate (model A5, hue 210, lot B27, dimension $0.31 \times 0.31 \mathrm{~m}$, thickness $0.75 \mathrm{~cm})$;

b) Porcelanate 1 (model Cara-A, classification/lot i-24, dimension $0.35 \times 0.35 \mathrm{~m}$, thickness $0.75 \mathrm{~cm})$;

c) Porcelanate 2 (model Atenas, lot 045/11, dimension $0.32 \times 0.32 \mathrm{~m}$, thickness $0.70 \mathrm{~cm})$;

d) Marble (model Pinta verde, hue White, dimension $0.20 \times 1.00 \mathrm{~m}$, thickness $2.00 \mathrm{~cm})$

e) Travertine (dimension $0.20 \times 1.00 \mathrm{~m}$, thickness $2.00 \mathrm{~cm})$

f) Granite (model Corumbá dimension $0.20 \times 1.00 \mathrm{~m}$, thickness $2.00 \mathrm{~cm})$;

g) Granite (model Verde Ubatuba dimension $0.20 \times 1.00 \mathrm{~m}$, thickness $2.00 \mathrm{~cm})$

h) Clay Slates (dimension $0.40 \times 0.40 \mathrm{~m}$, thickness $0.70 \mathrm{~cm}$ )

i) Stone Plate (model Miracema, dimension $0.10 \times 0.25 \mathrm{~m}$, thickness $2.00 \mathrm{~cm})$;

j) Concrete Tile (model Classic Capa-Canal, hue gray, dimension $0.10 \times 0.25 \mathrm{~m}$, thickness $2.00 \mathrm{~cm}$ ).

\subsection{Equipment and Measurement Times}

Noise was measured using a sound level meter (Brüel \& Kjær, model 2260), were measured with respect to frequency in $1 / 3$ octave bands between $100-8,000 \mathrm{~Hz}$ Each measurement was for $10 \mathrm{~s}$.

\subsection{Measurement Arrangement and Noise Meter Positions}

This research applies the commonly used $\mathrm{L}_{\mathrm{p}(\mathrm{ST})}$ proposed by ISO $3744: 2010$ to characterize sound pressure levels and $\mathrm{L}_{\mathrm{EX}, 8 \mathrm{~h}}$ proposed by ISO 9612:2009 to characterize noise exposure levels. The methodology considered the noise generated in the right ear of the operator and around the source (1.2 $\mathrm{m}$ from the floor and $2 \mathrm{~m}$ from source). We used wind shield on the microphone of the meter. Figure 1 illustrates the measurement points and their physical arrangement, and the central shaded box represents the noise source located under a reflecting plane.

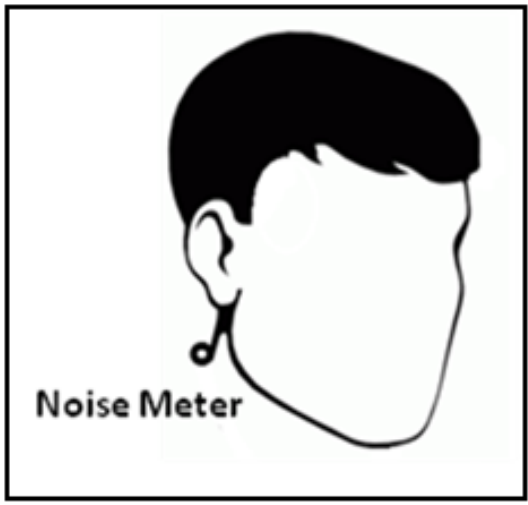

(a)

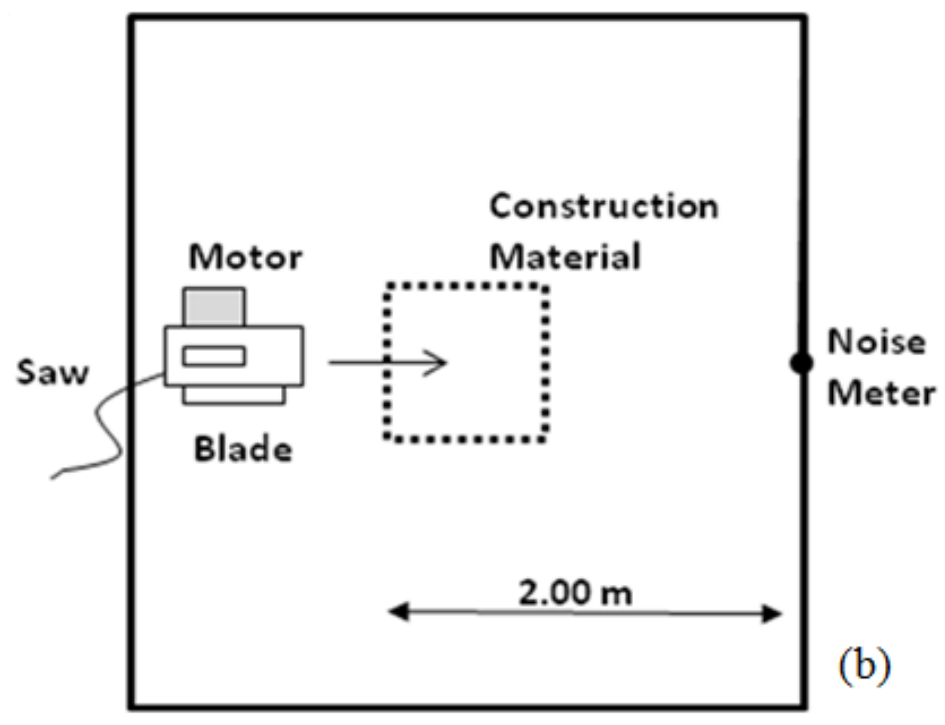

(b)

Figure 1. (a)Noise meter at saw operator and (b) measurement arrangement with the noise meter at 2 meters from the source

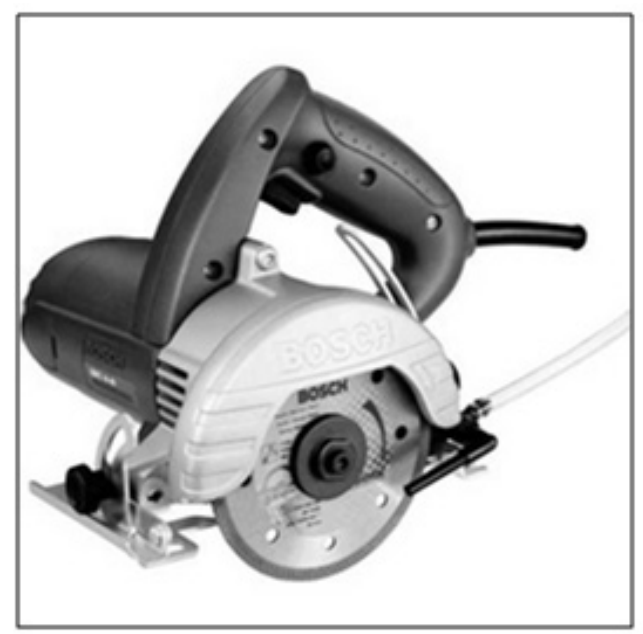

(a)

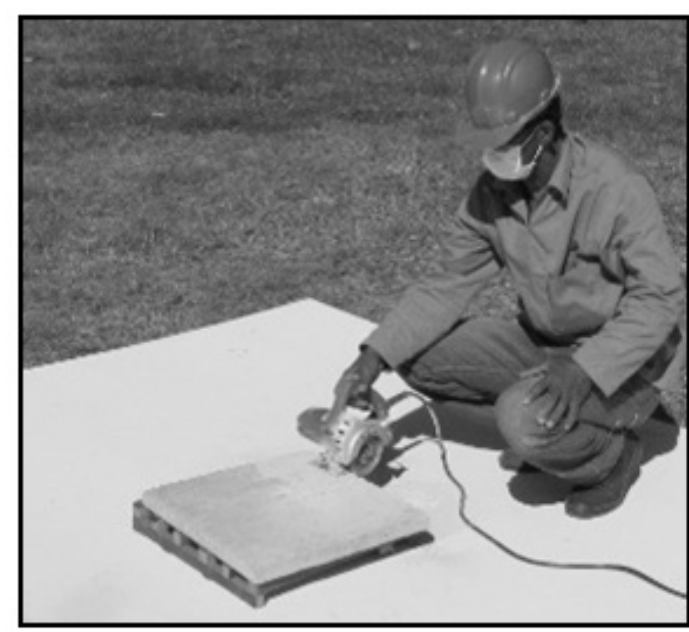

(b)

Figure 2. (a) The tested masonry saw and (b) its use in an open field 
Figure 2 (a) shows the masonry saw used. Figure 2 (b) depicts it cutting materials in an open field.

\subsection{Calculations}

The sound pressure levels from the measurements $\left(\mathrm{L}_{\mathrm{p}(\mathrm{ST})}\right)$, proposed by ISO 3744:2010, were determined as follows:

$$
\overline{L_{p(S T)}^{\prime}}=10 \lg \left[\frac{1}{N_{M}} \sum_{i=1}^{N_{M}} 10,1 L_{p i(S T)}^{\prime}\right] \mathrm{dB},
$$

where $L_{p(\mathrm{ST})}^{\prime}$ is the mean frequency-band sound pressure level in decibels $(\mathrm{dB})$ measured from the positions in the measurement suface test (ST), and $N_{\mathrm{M}}$ is the number of microphone positions used in the measurement surface.

The average A-weighted noise exposure levels for a nominal 8-h working day $\left(\mathrm{L}_{\mathrm{EX}, 8 \mathrm{~h}}\right)$ proposed by ISO 9612:2009, were determined as follows:

$$
L_{E X, 8 h}=L_{p, A, e q T_{e}}+10 \lg \left[\frac{T_{e}}{T_{0}}\right] \mathrm{dB},
$$

where:

$L_{p, \mathrm{~A}, \mathrm{eq} T \mathrm{e}}$ is the A-weighted equivalent continuous sound pressure level for $T_{\mathrm{e}}$;

$T_{\mathrm{e}} \quad$ is the effective duration, in hours, of the working day;

$T_{0} \quad$ is the reference duration, $T_{0}=8 \mathrm{~h}$.
According to ISO $9612: 2009, \mathrm{~L}_{\mathrm{EX}}$, $8 \mathrm{~h}$ is defined as the average A-weighted noise exposure level for a nominal 8$\mathrm{h}$ working day. It is measured by the unit decibel $(\mathrm{dB})$ which represents the sound level. $\mathrm{L}_{\mathrm{EX}, 8 \mathrm{~h}}$ creates a uniform evaluation criterion for workers subject to different working hours. To calculate $\mathrm{L}_{\mathrm{EX}}$, 8h, the index $\mathrm{L}_{\mathrm{Aeq}, \mathrm{T}}$, which reflects the A-weighted equivalent continuous sound pressure level in $\mathrm{dB}$ over a period of time $(\mathrm{T})$, is selected to be measured in this study.

Because construction noise is generally varying and intermittent, it is reasonable to use the continuous steady-state indicator $\mathrm{L}_{\mathrm{Aeq}, \mathrm{T}}$, which is calculated by taking an average of the fluctuant noise level during a period of time. $\mathrm{L}_{\mathrm{EX}, 8 \mathrm{~h}}$ is calculated by normalizing $\mathrm{L}_{\mathrm{Aeq}, \mathrm{T}}$ to an $8-\mathrm{h}$ working day according to the calculation procedures proposed in ISO 9612:2009.

\section{Results and Discussion}

\subsection{Noise Generated Distanced 2 Meters from Source}

The values of the sound pressure levels (Lp) generated in the cutting operations as a function of the frequency for different load conditions, without load and the standard deviation are presented in Table 1 . In the calculation of the standard deviation, sound pressure levels Background noise and no-load condition. It stands out, in the last line, the global levels in $\mathrm{dB}$ and $\mathrm{dB}(\mathrm{A})$.

\begin{tabular}{|c|c|c|c|c|c|c|c|c|c|c|c|c|c|}
\hline Frequency & $\begin{array}{c}\text { Background } \\
\text { Noise }\end{array}$ & Unloaded & $\begin{array}{l}\text { Ceramic } \\
\text { Plate }\end{array}$ & Marble & $\begin{array}{l}\text { Granite } \\
\text { Corumba }\end{array}$ & $\begin{array}{l}\text { Granite } \\
\text { Ubatuba }\end{array}$ & Travertine & $\begin{array}{l}\text { Clay } \\
\text { Slate }\end{array}$ & Porc. 1 & Porc. 2 & $\begin{array}{c}\text { Stone } \\
\text { Miracema }\end{array}$ & $\begin{array}{l}\text { Concrete } \\
\text { Tile }\end{array}$ & $\begin{array}{c}\text { Standard } \\
\text { Deviation }\end{array}$ \\
\hline$[\mathrm{Hz}]$ & {$[d B]$} & {$[d B]$} & {$[d B]$} & {$[d B]$} & {$[d B]$} & {$[d B]$} & {$[d B]$} & {$[d B]$} & {$[d B]$} & {$[d B]$} & {$[d B]$} & {$[d B]$} & \\
\hline 100 & 49.5 & 51.4 & 51.0 & 47.4 & 48.2 & 47.5 & 48.2 & 50.9 & 51.3 & 51.2 & 53.1 & 49.5 & 1.9 \\
\hline 125 & 48.6 & 48.5 & 48.3 & 47.2 & 47.4 & 48.6 & 48.0 & 52.3 & 55.7 & 50.8 & 52.3 & 51.0 & 2.7 \\
\hline 160 & 45.2 & 48.0 & 47.5 & 49.1 & 53.8 & 53.4 & 52.4 & 57.8 & 64.5 & 62.8 & 52.5 & 55.2 & 5.4 \\
\hline 200 & 42.4 & 53.7 & 55.0 & 55.6 & 55.0 & 55.5 & 54.3 & 56.0 & 63.0 & 64.0 & 50.5 & 55.2 & 4.0 \\
\hline 250 & 40.6 & 47.5 & 47.9 & 47.3 & 47.7 & 56.7 & 47.1 & 50.0 & 50.4 & 49.6 & 49.5 & 54.5 & 3.2 \\
\hline 315 & 37.4 & 45.4 & 53.4 & 49.3 & 56.0 & 59.8 & 49.6 & 58.2 & 61.7 & 55.0 & 55.1 & 52.5 & 41 \\
\hline 400 & 34.9 & 51.9 & 65.2 & 59.3 & 61.9 & 63.6 & 62.0 & 65.3 & 67.3 & 65.0 & 62.4 & 66.6 & 2.5 \\
\hline 500 & 34.9 & 57.9 & 64.0 & 59.5 & 60.6 & 68.8 & 60.3 & 70.4 & 73.4 & 74.3 & 64.3 & 69.9 & 5.5 \\
\hline 630 & 33.6 & 60.3 & 65.9 & 64.5 & 69.2 & 72.3 & 65.4 & 75.8 & 81.8 & 75.2 & 67.2 & 70.9 & 5.5 \\
\hline 800 & 33.6 & 64.8 & 75.2 & 67.2 & 72.2 & 73.0 & 69.2 & 81.7 & 83.4 & 79.5 & 67.8 & 70.3 & 5.8 \\
\hline 1000 & 33.8 & 71.1 & 75.6 & 66.5 & 72.2 & 69.5 & 69.2 & 77.9 & 77.5 & 77.1 & 68.4 & 73.0 & 4.2 \\
\hline 1250 & 33.5 & 70.4 & 77.8 & 70.2 & 73.5 & 74.4 & 73.1 & 79.3 & 87.3 & 84.2 & 74.0 & 78.4 & 5.3 \\
\hline 1600 & 33.2 & 68.0 & 81.1 & 72.1 & 72.0 & 73.8 & 73.7 & 84.3 & 82.8 & 85.3 & 73.9 & 76.7 & 5.3 \\
\hline 2000 & 31.5 & 74.7 & 79.7 & 76.7 & 77.5 & 76.8 & 77.2 & 81.8 & 85.2 & 82.6 & 76.9 & 76.0 & 3.1 \\
\hline 2500 & 29.6 & 74.0 & 78.6 & 75.5 & 79.1 & 77.7 & 76.9 & 83.5 & 89.7 & 83.5 & 77.5 & 75.3 & 4.5 \\
\hline 3150 & 27.6 & 75.3 & 84.1 & 76.1 & 80.3 & 78.9 & 76.9 & 83.5 & 89.5 & 86.7 & 78.1 & 76.4 & 4.7 \\
\hline 4000 & 27.0 & 73.4 & 84.7 & 77.7 & 82.1 & 82.3 & 80.2 & 89.1 & 89.9 & 88.7 & 81.9 & 76.3 & 4.7 \\
\hline 5000 & 25.9 & 73.0 & 90.8 & 79.4 & 88.8 & 86.9 & 84.9 & 91.2 & 92.3 & 90.1 & 87.7 & 79.6 & 4.6 \\
\hline 6300 & 26.0 & 74.7 & 87.2 & 81.7 & 88.4 & 88.3 & 83.8 & 92.4 & 91.7 & 91.1 & 87.9 & 83.7 & 3.6 \\
\hline 8000 & 25.3 & 76.8 & 87.6 & 83.3 & 88.0 & 87.4 & 85.0 & 90.7 & 91.2 & 90.7 & 88.0 & 80.6 & 3.4 \\
\hline $\begin{array}{c}\text { Lp Linear } \\
{[\mathrm{dB}]}\end{array}$ & 54.0 & 83.9 & 95.2 & 88.3 & 94.1 & 93.4 & 90.7 & 98.0 & 99.5 & 97.7 & 93.5 & 88.9 & 3.8 \\
\hline $\begin{array}{c}\text { Lp Global } \\
d B(A)\end{array}$ & 45.7 & 83.5 & 94.4 & 86.8 & 92.7 & 91.9 & 89.5 & 97.0 & 99.1 & 96.9 & 91.9 & 88.3 & 4.0 \\
\hline
\end{tabular}

Table 1. Sound levels generated 2 meters away from the operations with the masonry saw 
The mean of the sound pressure levels of the different load conditions in the frequency-dependent operations is shown in Figure 3, with the following lines being highlighted: red (mean Lp), green (no-load condition) and blue (background noise).

The comparative of the sonorous spectra points increase increasing of the level between the frequencies of 100 and $4,000 \mathrm{~Hz}$, varying of 50 to $90 \mathrm{~dB}$. Between 5,000 and $8,000 \mathrm{~Hz}$ the values remain relatively constant. In the results of the noise levels, a significant increase of the noise level in 160 and $200 \mathrm{~Hz}$ and a decrease in $250 \mathrm{~Hz}$ is observed, which is associated with the fundamental frequency of the marble saw that operates at 12,000 RPM.

It is observed that the noise levels in the operations with the porcelanate 1 and porcelanate 2 are higher in relation to the other materials of construction specially operated in the frequencies of 160, 200,630, 800 and $1250 \mathrm{~Hz}$. Differences in source sound levels when operated with load compared to background noise were above $10 \mathrm{~dB}$ from $200 \mathrm{~Hz}$, indicating that there is no influence of background noise from 200 to $8000 \mathrm{~Hz}$. However, the importance of correct corrections and analyses in relation to background noise in the bands of 100 to $160 \mathrm{~Hz}$ is emphasized.

\subsection{Analysis of Sound Levels at the Ear Operator}

For an ergonomic analysis of the sound pressure levels generated, Figure 4 shows the sound pressure level in $\mathrm{dB}$ (A), generated in the right ear of the masonry saw operator.

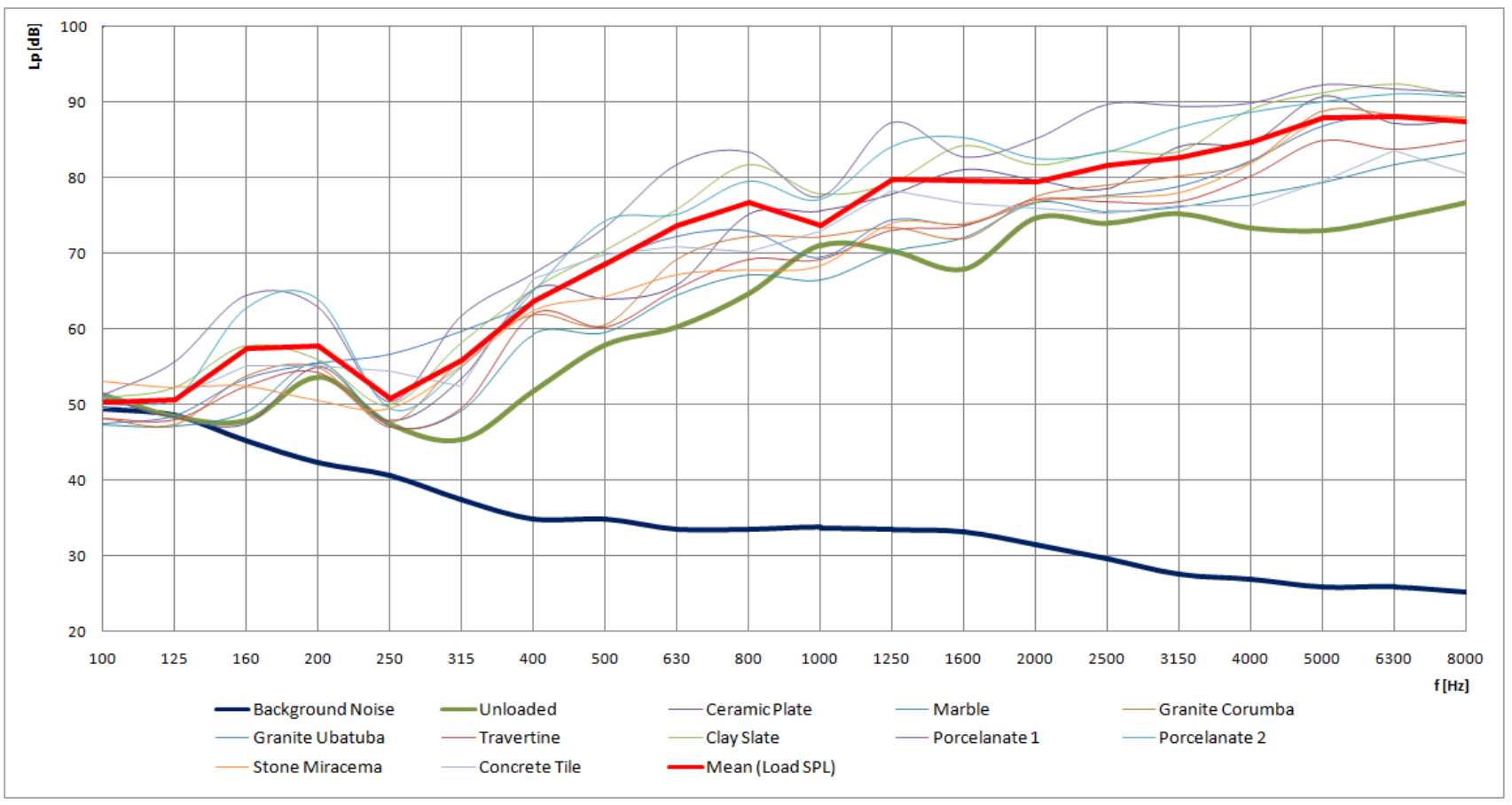

Figure 3. Average sound spectrum generated for different building materials, no load condition and background noise

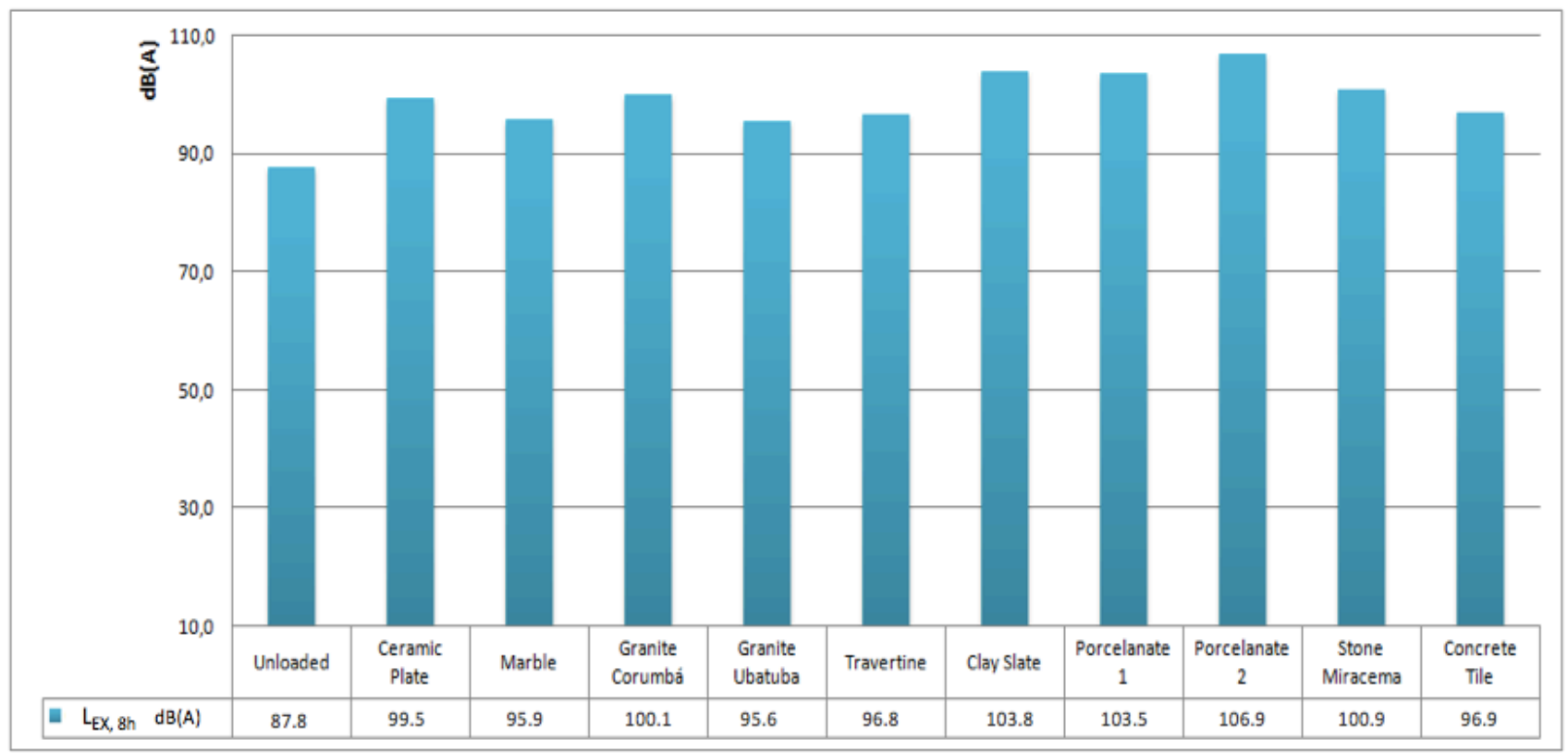

Figure 4. Comparative analysis of the sound levels generated in the operator's right ear 
The highest sound level for the load condition is observed in the cut of porcelanate 2 which generated $106.9 \mathrm{~dB}(\mathrm{~A})$ while the lowest level occurs for the cutting of the Marble with $99.5 \mathrm{~dB}(\mathrm{~A})$. The no-load condition generated $87.8 \mathrm{~dB}(\mathrm{~A})$, representing a difference ranging from 7.8 to $19.1 \mathrm{~dB}$ in relation to the materials operated with the masonry saw. From the occupational point of view, the sound levels generated in the operations of masonry saw with the operator with load exceeded the limits of tolerance allowed by the legislation of many countries, that establishes the maximum level of $85 \mathrm{~dB}$ (A) for an 8-hour work day without the necessary protective measures.

\section{Conclusions}

The measurement setup (i.e., the positioning of the source and measurement locations) complied with ISO 3744:2010 and ISO 9612:2009, which were adapted for the specific assessment of the masonry saw, its conditions of loading, and operation. Higher sound pressures were recorded during the cutting of the different materials than during the free running of the non-cutting saw. Average sound pressure levels were calculated by correcting for the sound pressure level at each measurement point, the background noise and the average A-weighted noise exposure level for a nominal 8-h working day.

It was possible to evaluate the values of the sound pressure levels generated in the cutting operations as a function of the frequency for different load conditions, without load and the standard deviation. The noise levels were unstable and inaccurate at lower frequencies; they were higher at higher frequencies, but became more stable level in the range $1-4 \mathrm{kHz}$. There is no influence of background noise from $200-8 \mathrm{kHz}$.

In terms of noise exposure, the sound levels generated in the operations of masonry saw with the operator with load exceeded the limits of tolerance allowed by the legislation of many countries, that establishes the maximum level of $85 \mathrm{~dB}$ (A) for an 8-hour work day without the necessary protective measures and it was possible to characterize the activity of masonry saw operates cutting building materials like as unhealthy, showing that they deserve a special care in the information to the user's of the equipment.

It should be noted that indoor environments subject to reflections on the walls, floors and ceilings indicate that the noise levels generated by the masonry saw will reach even higher levels. Other factors that could lead to increased noise in the operations could be the used machines, with higher vibrations, lack of proper regulation. It may also mention the inappropriate or excessive use of abrasive blade, untrained operator, among other factors that could be object of a complementary study oh this article.

Studies of sound levels that consider the load to be operated in the operation of masonry saw is relevant and contributes in the anticipation and recognition of the physical risks that will be exposed the operator and the workers in the environs of the source in their work environment, in their work activities, regardless of the activities performed.

Noise excess removal in the workplace is not just a legal responsibility of the companies, as it is also involved with the market interests of an organization. The safer and healthier a workplace is, the fewer probabilities of absenteeism, accidents and low performance, and consequently, cost savings will be achieved. This study also contributes to the analysis of occupational noise generation, considering the difficulties in obtaining previously reported values of the sound spectrum of masonry saws.

\section{References}

[1] STEPHENSON, M. R. National Research Agenda for the Prevention of Occupational Hearing Loss. Semin Hear Journal. Thieme Medical Publishers, New York, USA, 2013.

[2] WORLD HEALTH ORGANIZATION (WHO). Resumé d'Orientation des directives de ROMS Relatives au Bruit dans 1'Environmental. Available at: http://www.who.int, Switzerland, 2011.

[3] NIOSH - National Institute for Occupational Safety and Health. Occupational noise exposure - revised criteria 2011. Ohio: U.S. Department of Health and Human Services. Available at: http://www.cdc.gov/niosh. USA, 2013.

[4] BALLESTEROS, M. J.; FERNÁNDEZ, M. D.; QUINTANA S.; BALLESTEROS, J. A.; GONZÁLEZ I. Noise emission evolution on construction sites. Measurement for controlling and assessing its impact on the people and on the environment. Building and Environment Journal, Volume 45, Issue 3, Pages 711-717.

[5] SINDUSCON / FGV PROJECTS. 55 ${ }^{\text {th }}$ National Survey of Construction Industry. Available in http://www.sindusconsp.com.br, Sao Paulo, Brazil, June, 2013.

[6] SJÖSTRÖM, M.; LEWNÉ, M.; ALDERLING, M.; WILLIX, P.; BERG, P.; GUSTAVSSON, P.; A Job-Exposure Matrix for Occupational Noise: Development and Validation. Annals of Occupational Hygiene, Available at:

http://annhyg.oxfordjournals.org/content/early/2013/02/01/annhy g.met001.full.pdf, UK, 2013.

[7] OLIVEIRA, J. P. B. Optimization of constructive processes through the integration of technology in the construction industry. ROCA Repository - Federal Technological University of Parana. Curitiba, Brazil, 2013.

[8] SEIXAS, N. S.; NEITZEL, R.; STOVER, B.; SHEPPARD, L.; FEENEY, P.; MILLS, D.; KUJAWA, S. 10-Year prospective study of noise exposure and hearing damage among construction workers. Occupational \& Environmental Medicine Journal; Volume 69:643-650, Seattle, USA, 2012.

[9] ANFACER (BRAZILIAN ASSOCIATION OF CERAMIC MANUFACTURERS). Industry figures. Available at http://www.anfacer.com.br. Sao Paulo, Brazil, 2015.

[10] BRAZILIAN ASSOCIATION OF TECHNICAL STANDARDS ABNT NBR 15910:2010 - Tools portable electric motor operated Safety: Particular requirements for masonry saw. 15p, Rio de Janeiro, Brazil, 2010.

[11] INTERNATIONAL ORGANIZATION FOR STANDARDIZATION ISO 3744 - Acoustics - Determination of sound power levels of noise sources using sound pressure: Engineering methods for an essentially free field over a reflecting plane. Switzerland, 2010.

[12] INTERNATIONAL ORGANIZATION FOR STANDARDIZATION. ISO 9612 - Acoustics - Determination of occupational noise exposure: Engineering method. Switzerland, 2010. 